\title{
Identifying and managing patients at risk of severe allergic reactions to food: report from two iFAAM workshops
}

Roberts, Graham ; Allen, Katie ; Ballmer-Weber, Barbara ; et al

\begin{abstract}
Food allergy affects a small but important number of children and adults. Much of the morbidity associated with food allergy is driven by the fear of a severe reaction and fatalities continue to occur. Foods are the commonest cause of anaphylaxis. One of the aims of the European Union-funded Integrated Approaches to Food Allergen and Allergy Risk Management (iFAAM) project was to improve the identification and management of children and adults at risk of experiencing a severe reaction. A number of interconnected studies within the project have focused on quantifying the severity of allergic reactions; the impact of food matrix, immunological factors on severity of reactions; the impact of co-factors such as medications on the severity of reactions; utilizing single-dose challenges to understand threshold and severity of reactions; and community studies to understand the experience of patients suffering real-life allergic reactions to food. Associated studies have examined population thresholds and co-factors such as exercise and stress. This paper summarizes two workshops focused on the severity of allergic reactions to food. It outlines the related studies being undertaken in the project indicating how they are likely to impact on our ability to identify individuals at risk of severe reactions and improve their management.
\end{abstract}

DOI: https://doi.org/10.1111/cea.13516

Posted at the Zurich Open Repository and Archive, University of Zurich

ZORA URL: https://doi.org/10.5167/uzh-177247

Journal Article

Accepted Version

Originally published at:

Roberts, Graham; Allen, Katie; Ballmer-Weber, Barbara; et al (2019). Identifying and managing patients at risk of severe allergic reactions to food: report from two iFAAM workshops. Clinical and Experimental Allergy, 49(12):1558-1566.

DOI: https://doi.org/10.1111/cea.13516 
PROFESSOR GRAHAM ROBERTS (Orcid ID : 0000-0003-2252-1248)

PROFESSOR KATRINA J ALLEN (Orcid ID : 0000-0002-1921-4493)

DR AUDREY DUNNGALVIN (Orcid ID : 0000-0002-1540-3959)

DR RONALD VAN REE (Orcid ID : 0000-0003-0767-0894)

PROFESSOR PAUL J. TURNER (Orcid ID : 0000-0001-9862-5161)

Article type : Opinion or Debate

Identifying and managing patients at risk of severe allergic reactions to food: report from two iFAAM workshops

Graham Roberts ${ }^{1,2,3}$, Katie Allen ${ }^{4,5,6}$, Barbara Ballmer-Weber ${ }^{7,8,9}$, Andrew Clark ${ }^{10}$, Rene Crevel ${ }^{11}$, Audrey Dunn Galvin ${ }^{12}$, Montserrat Fernandez-Rivas ${ }^{13}$, Kate E. C. Grimshaw ${ }^{1}$, Jonathan O’B Hourihane ${ }^{14}$, Lars K. Poulsen ${ }^{15}$, Ronald van Ree ${ }^{16}$ Lynn Regent ${ }^{17}$ Ben Remington ${ }^{18}$, Sabine Schnadt ${ }^{19}$, Paul J. Turner ${ }^{20}$, E. N. Clare Mills ${ }^{6}$

\section{Affiliations}

1. University of Southampton Faculty of Medicine, Southampton, UK

2. NIHR Southampton Biomedical Research Centre, University Hospital Southampton NHS

Foundation Trust, Southampton, UK

3. The David Hide Asthma and Allergy Research Centre, St Mary's Hospital, Isle of Wight, UK

4. Murdoch Children's Research Institute, Royal Children's Hospital, Australia

5. Department of Paediatrics, University of Melbourne, Parkville, Australia

This article has been accepted for publication and undergone full peer review but has not been through the copyediting, typesetting, pagination and proofreading process, which may lead to differences between this version and the Version of Record. Please cite this article as doi: 10.1111/CEA.13516

This article is protected by copyright. All rights reserved 
6. Institute of Inflammation and Repair, University of Manchester, UK

7. Allergy Unit, Department of Dermatology, University Hospital, University of Zurich, Zurich, Switzerland

8 Faculty of Medicine, University of Zürich, Zürich, Switzerland

9. Clinic for Dermatology and Allergology, Kantonsspital St. Gallen, St. Gallen, Switzerland

10. Cambridge University Hospitals NHS Foundation Trust, Cambridge, UK

11. René Crevel Consulting Ltd, Bedford, UK; Formerly: Safety and Environmental Assurance Centre, Unilever, Colworth Science Park, Sharnbrook, Bedford, UK

12. Applied Psychology and Paediatrics and Child Health, University College Cork, Cork, Ireland

13. Servicio de Alergia, Hospital Clınico San Carlos, IdISSC, ARADyAL, Universidad

Complutense, Madrid, Spain

14. Paediatrics and Child Health, University College Cork, Cork, Ireland

15. Allergy Clinic, Copenhagen University Hospital at Gentofte, Copenhagen, Denmark

16. Departments of Experimental Immunology and of Otorhinolaryngology, Academic Medical Center, University of Amsterdam, Amsterdam, The Netherlands

17. The Anaphylaxis Campaign, Farnborough, UK

18. TNO, Zeist, The Netherlands

19. German Allergy and Asthma Association, Mönchengladbach, Germany

20. Section of Paediatrics (Allergy and Infectious Diseases), Imperial College London, London, UK

Address for correspondence

Professor E. N. Clare Mills, PhD, Institute of Inflammation and Repair, Manchester Academic Health Science Centre, Manchester Institute of Biotechnology, University of Manchester, 131, Princess St, Manchester M1 7DN, United Kingdom. E-mail: clare.mills@manchester.ac.uk.

Word count: currently 4500

Key words: allergy, anaphylaxis, co-factors, food, severity 


\section{Abstract}

Food allergy affects a small but important number of children and adults. Much of the morbidity associated with food allergy is driven by the fear of a severe reaction, and fatalities continue to occur. Foods are the commonest cause of anaphylaxis. One of the aims of the European Union funded Integrated Approaches to Food Allergen and Allergy Risk Management (iFAAM) project was to improve the identification and management of children and adults at risk of experiencing a severe reaction. A number of interconnected studies within the project have focused on quantifying the severity of allergic reactions; the impact of food matrix, immunological factors on severity of reactions; the impact of co-factors such as medications on the severity of reactions; utilising single dose challenges to understand threshold and severity of reactions; and community studies to understand the experience of patients suffering real-life allergic reactions to food. Associated studies have examined population thresholds, and co-factors such as exercise and stress. This paper summarises two workshops focused on the severity of allergic reactions to food. It outlines the related studies being undertaken in the project indicating how they are likely to impact on our ability to identify individuals at risk of severe reactions and improve their management.

This article is protected by copyright. All rights reserved 


\section{$1 \quad$ Background}

2 Food allergy affects around $5 \%$ of preschool children and $2 \%$ of school children and adults (1).

3 The prevalence has increased in recent decades with a doubling in peanut allergy (2) and similar

4 increases in hospitalisations due to anaphylaxis in Europe, USA and Australia (3). Food allergy is

5 the commonest cause of anaphylaxis (4), a systemic and potentially life-threatening allergic

6 reaction (5). Anxiety surrounding the fear of a severe allergic reaction has a major impact on

7 food-allergic patients and their families. For example, impaired quality of life is seen with the

8 necessary avoidance strategies, need to carry rescue medication and the associated fear of an

9 allergic reaction (6). Food-induced allergic reactions result in many presentations to hospital each 10 year and there are, often well publicised, cases of fatal anaphylaxis (7). Unfortunately these

11 severe allergic reactions are not predictable (8), and individuals with the same food allergy can

12 have very different reactions following ingestion due to co-factors $(3,9)$. Such co-factors include,

13 among others, exercise, viral infections and several medications, whose presence around the

14 time of reaction may be associated with the development of more severe symptoms. The risks

15 associated with having food allergy are primarily described by the risk of having a severe allergic

16 reaction. The management of patients with food allergy is also driven by risk. With increasing risk,

17 more rigorous avoidance strategies are recommended and adrenaline auto-injectors are

18 prescribed to manage any future severe allergic reactions (5).

20 Integrated Approaches to Food Allergen and Allergy Risk Management (iFAAM) is a European

21 Union funded FP7 project. iFAAM aims to reduce the burden of food allergy through a number of

22 integrated activities. The project has developed evidence-based approaches and tools to improve 23 both the management of allergens in food as well as the management of food allergy. Many of 24 these activities are focused on the severity of allergic reactions. This paper is a summary from 25 two workshops. Firstly an iFAAM workshop held in Rome, Italy on Saturday $15^{\text {th }}$ October 2016. 26 The aims of the workshop were to consider how best to (i) identify patients at risk of severe 27 reactions and situations that may impact on severity of reaction, and (ii) manage patients at risk 28 of severe reactions, particularly around high risk situations. Secondly a ILSI Europe Food Allergy 29 Symposium held in Madrid, Spain between $18^{\text {th }}$ and $20^{\text {th }}$ April 2018 where the final iFAAM project 30 findings were reviewed and discussed. The paper describes the iFAAM severity activities and 31 how they may lead onto improved allergen and allergy management for consumers with food 32 allergies. 


\section{Quantifying the severity of allergic reactions}

35 Allergic reactions to food vary in severity, ranging from isolated oral symptoms, to relatively mild 36 cutaneous and gastrointestinal symptoms and to potentially life-threatening respiratory and 37 cardiovascular features (5). Healthcare professionals use the severity of a reaction to guide 38 treatment for that event and to inform future management of the patients. Being able to accurately 39 assess and describe the symptoms and signs of severe allergic reactions is therefore vital. A 40 number of systems have been developed to quantify the severity of allergic reactions to different 41 agents and in various circumstances, for example: venom $(10,11)$, food $(11-18)$, drugs $(19,20)$ 42 and adverse reactions to allergen immunotherapy $(21,22)$. None are in widespread use, perhaps 43 because none is ideal. They were all developed using expert opinion, and none has been 44 validated. Major limitations of the current schemes include a lack of discrimination between non45 anaphylactic reactions of varying severity, lack of applicability to multiple allergen types, and they 46 are not readily translatable into clinical management. For more details, see the recent European 47 Academy of Allergy and Clinical Immunology position paper (23).

49 To start to address these gaps, iFAAM has developed a Food Allergy Severity Score (FASS) with 50 two linked formats, a numerical nFASS developed with mathematical modelling and an ordinal 51 oFASS developed by experts' consensus with 5 grades that can be reduced to 3 (mild-moderate52 severe) to facilitate rapid assessment and ease of communication within most clinical settings. 53 The two scores have undergone internal validation using the EuroPrevall outpatient clinic 54 database (24), and external validation using different data sets that cover different foods, 55 paediatric and adult patients, and the whole spectrum of severity in food allergy. A manuscript 56 covering the development and validation will be submitted for publication in 2019. Further work is 57 planned to validate the system with other allergic triggers.

59 The availability of an appropriately developed and validated severity scoring tool will have an 60 important impact on patient care. A harmonised approach to defining severity in different 61 populations will allow data from different studies to be directly compared. Given the relationship 62 between past and future severity of reactions, this would allow the development of better 63 prediction models to identify patients at risk of future anaphylaxis. Clinically, the oFASS scale 64 should improve communication of reaction severity between primary care, acute providers and 65 allergy specialists as well as patients. This should enable specialists to better define individuals who may need to take additional precautions. The nFASS is expected to be used as an outcome 
measure in research trials; to compare severity between populations and triggers; and to analyse

the impact of other factors (as discussed below) and interventions in food allergy severity.

\section{Impact of food matrix on severity (and threshold) of allergic reactions}

71 The food matrix can affect the uptake of nutrients in the same way that the formulation of different 72 drugs may affect their absorption $(25,26)$. This phenomenon results from the physicochemical 73 nature of the food matrix - either the natural structure of plant and animal foods (formed of 74 organelles, cells and tissues), or the fabricated foods (such as gels, dispersions, foams and 75 emulsions). Allergens can also become entrained in the structures formed by these other food 76 components. The food matrix affects the amount of a nutrient in the gut lumen which is available, 77 after digestion, to be absorbed by the body, a property generally known as bio-accessibility $78(25,26)$. Coming from the field of molecular nutrition, this concept is relevant to understanding 79 how food allergens are released from food and interact with effector cells in the body to elicit an 80 allergic reaction.

82 The first description of a matrix effect on clinical reactivity to foods was a repeat food challenge 83 study in four patients where the fat content of a chocolate-based challenge vehicle was increased 84 to $31.5 \%$ from $22.9 \%(\mathrm{w} / \mathrm{w}$ ) by the addition of a white, high melting point bakery fat (27). Three 85 patients did not experience the mild oral symptoms that generally precede a reaction and 86 consequently consumed at least a 10-fold higher dose of peanut in the higher fat challenge. 87 These observations led to the hypothesis that the allergen was less bio-accessible in the oral 88 cavity when presented in the higher fat matrix. However, it is likely that the melting point of the 89 chocolate challenge was increased from $29-32^{\circ} \mathrm{C}$ by the use of a high melting point $\left(47-48^{\circ} \mathrm{C}\right)$ fat, 90 as well as altering the fat crystal structure of the chocolate. A comparison of a water continuous 91 chocolate dessert matrix and dark chocolate bars in seven patients with either peanut or hazelnut 92 allergy showed the chocolate bar $(35 \%(\mathrm{w} / \mathrm{w})$ fat) resulted in a higher cumulative threshold dose 93 or reaction than the dessert matrix (8\% (w/w) fat) (28). Magnetic resonance imaging (MRI) 94 showed the gastric residence time for the chocolate bar was much longer than the dessert which 95 might explain the delay in development of symptoms during the challenge with the chocolate bar 96 (28). There is also evidence that presentation of allergens in a baked matrix requires a higher 97 dose to be administered to elicit a reaction. For example, cow's milk allergic patients have been 98 found to reacted at lower doses to milk in a screening challenge than they did in the up-dosing for 99 oral immunotherapy with milk in a baked muffin matrix (29). However other studies have failed to 
show a similar matrix effect with egg and cow's milk $(30,31)$. An impact on the threshold dose and 101 severity of reactions was also observed in a group of hazelnut allergic patients when capsules 102 were used to deliver challenge doses, rather than a complex pudding matrix (32). In this study the 103 average threshold dose was increased by 3-fold, the lowest observed adverse effect level being 104 increased by 10 -fold and eight subjects experiencing no reaction even after consumption of $10 \mathrm{~g}$ 105 of hazelnut.

107 Insights are being gained into the mechanisms whereby the food matrix might affect allergen bio108 accessibility through in vitro digestion studies, using either batch or dynamic models of digestion. 109 An issue remains regarding the validation of such models using human studies, either by 110 analysing the intestinal contents from ileostomy patients or from intubation studies, although the 111 latter are limited to the study of liquid meals because of the constraints of nasogastric sampling. 112 However, studies are lacking directly linking in vivo studies on clinical reactivity to foods, and in 113 vitro studies investigating bio-accessibility of allergens during mastication and gastro-intestinal 114 digestion, and subsequent uptake into the circulation. It is inevitable that the number of studies 115 where repeat challenges have been undertaken in the same study population are small, and 116 drawing conclusions about matrix effects in populations is difficult and may be misleading, 117 especially if differences in severity of reaction, but not threshold dose are to be defined.

119 Addressing these gaps is a major objective of the iFAAM project with focus being placed on 120 peanut. The differences between baked matrices (cookies) and a water continuous dessert matrix 121 have been investigated in the iFAAM project. Further studies will be required using the same 122 systematic approach to identify the common rules governing bio-accessibility of food allergens in 123 complex food matrices. Such studies will inform food allergen management plans and support 124 evidence-based risk assessment of novel foods. Such knowledge is crucial to assessing the 125 allergenic risks posed by new technologies, such as 3D printing of foods, and novel functional 126 ingredients being developed to improve nutritional quality of foods and address the grand 127 challenge of food security.

\section{The influence of intrinsic immunological factors on reaction severity}

130 Given the pathophysiology of IgE-mediated reactions, it seems likely that the nature of food 131 allergen-specific IgE plays a role in the severity of a reaction, since $\lg E$ is a prerequisite for a 
132 reaction to happen at all. For example, the qualitative nature of the IgE-response determines 133 whether a food allergic person may react to "stable" allergens (i.e. highly abundant digestion- or 134 processing-resistant allergens) such as the storage proteins of peanuts, tree nuts and seeds or to 135 "unstable" allergens such as the PR-10 related allergens cross-reacting with the birch pollen 136 allergen Bet $v 1$, such as hazelnut Cor a 1.04, apple Mal d 1, or even peanut Ara $\mathrm{h} 8$ (33). The 137 avidity and affinity of the specific IgE-allergen interaction has been associated with the likelihood 138 of an allergic response (34). Together with prior reaction history, this may help to predict the 139 likelihood of a future severe reaction in appropriate individuals. Looking at the specific $\lg E$ in a 140 more quantitative manner, such as relating a specific IgE-titre to severity, has generated 141 equivocal results (3).

142

143 Immunoglobulins of the IgG-isotype are not considered to play a pathogenic role in food 144 hypersensitivity and their measurement is discouraged as a diagnostic marker for food allergy 145 (5,35). It has however been speculated that non-lgE isotypes - also including IgA - may offer 146 protection from food-induced IgE-mediated reactions, in a manner similar to that believed to occur 147 during allergen-specific immunotherapy. For example, food-specific lgG4 was reported to block in 148 vitro reactions in basophils and mast cells to peanut (36). Little is known though as to whether 149 such antibodies provide real-life protection and can reduce severity of food-induced allergic 150 reactions. While this has been observed in studies of tolerance induction, there are few data to 151 indicate whether IgG isotypes are useful either for predicting outcome or severity of allergic 152 reactions at oral food challenge under medical supervision. In the iFAAM project, the prognostic 153 value of specific $\operatorname{lgG}_{4}$ was studied in a cohort of 137 patients with challenge proven peanut 154 allergy and 25 sensitized tolerant subjects. Although $\operatorname{lgG}$ and $\operatorname{lgG}_{4}$ over $\lg E$ ratios were indeed 155 found to be inversely associated with severity of reactions during challenge, they did not predict 156 challenge outcomes better than IgE alone (37).

158 Following the cross-linking of two or more receptor-bound IgE-molecules by allergens, effector 159 cells - primarily believed to be mast cells - become activated. Basophils may also contribute to 160 reaction severity, with evidence of both basophil activation and basophil trafficking in allergic 161 reactions due venom and food (38). The relationship between basophil activation/trafficking and 162 reaction severity needs to be further explored. Studies of the cellular compartment of IgE-induced 163 reactions, in particular mast cells, have been hampered by the question as to which anatomical 164 site actually constitutes the target organ in food allergy: when a food allergen enters the digestive 
tract, is it absorbed systemically and distributed to target organs such as the vascular system, the 166 lungs and the upper airways to induce local mast cell activation? Or does it activate mast cells 167 lining the digestive tract, resulting in the release of inflammatory mediators from the gut which are 168 then distributed systemically? Alternatively, allergen absorption may occur across the buccal 169 mucosa (39), resulting in rapid systemic allergen distribution independent of absorption distal to 170 the mouth: such rapid absorption may explain the observation that anaphylaxis can occur within 171 minutes of ingestion.

173 Human mast cells originate from hematopoietic stem cells residing in the bone marrow and bear 174 the surface markers CD34, CD117 and CD13. Mast cell progenitors leave the bone marrow and 175 travel by the circulation to the peripheral sites where they home to vascular endothelium and 176 enter peripheral tissues upon recruitment. In the tissue immature lineage mast cells fully develop 177 into mature granule-containing mast cells. The differentiation and maturation of mast cells is 178 directed by cytokines in the local microenvironment. Stem cell factor (SCF) is essential for mast 179 cell differentiation. SCF binds to CD117 (c-kit) and control development and survival of mast 180 cells. Recently published studies have used in vitro derived mast cells to delineate a possible 181 correlation between mast cells response to allergen and asthma or atopic status, $(40,41)$. Similar 182 studies would be needed to elucidate whether mast cells from food allergic patients are 183 predisposed to a higher activation level thus determining the severity of reactions in food allergy.

\section{The impact of medications as co-factors in allergic reactions}

186 The severity of allergic reactions to foods varies significantly - even within the same individual 187 and while differences in the exposure dose may contribute to this observation, severity is clearly 188 impacted upon by a range of other influences ("co-factors"), independent of dose. One co-factor 189 thought to be responsible for increasing the severity of reactions is medications. A knowledge of 190 the impact of specific medications on the severity of allergic reactions may allow us to provide 191 information to affected individuals to help them avoid risky situations.

193 Proton-pump inhibitors

194 Gastric enzymes, such as pepsins, require an acidic environment to function. Following treatment 195 with proton-pump inhibitors (PPI), which reduces gastric acidity to $\mathrm{pH} 4.0$ or higher, pepsin 196 becomes less active (42). Theoretically, this may prevent digestion-labile proteins with an 
197 allergenic potential from being fully degraded (43), resulting in sensitisation and the development 198 of clinical allergy. In one study, 5 of 153 patients treated with anti-ulcer medication for three 199 months developed specific IgE to hazelnut and clinical symptoms; three of them developed 200 symptoms under single-blind, placebo-controlled food challenges, with either pruritus or urticaria, 201 and the remaining two upon accidental ingestion, with OAS or urticaria (44). In another report, 202 patients with fish allergy underwent blinded food challenges with fish extract digested with gastric 203 enzymes at $\mathrm{pH} 2.0$ and 3.0. Fish extract digested at $\mathrm{pH} 3.0$ triggered reactions at 10 - to 30 -fold 204 lower cumulative challenge doses than extract treated at $\mathrm{pH}$ 2.0, and two of four patients reacted 205 only to the latter. These data suggest that impaired digestion might put the patients with food 206 allergy at a higher risk of developing symptoms at lower doses and at potential risk of more 207 severe allergic reactions (45). This effect, however, has not yet been demonstrated in a well208 controlled, double-blind, placebo-controlled food challenge (DBPCFC) setting, or in a larger study 209 cohort.

211 Given this, within the iFAAM project the impact of PPI on severity of food-induced allergy 212 symptoms and minimum eliciting dose has been studied at two geographically different centres, 213 Zurich and Madrid in a randomised double-blind placebo-controlled clinical trial (EUDRA CT $\mathrm{nr}$ 214 2015-001863-38), analysing food reactivity by DBPCFC. Patients with walnut allergy have 215 undergone three food challenges (two active, one placebo session) with a pre-treatment with 216 either PPI or placebo. Publication of results is expected in 2019.

217

218 Non-steroidal, anti-inflammatory drugs (NSAIDs)

219 NSAID-enhanced, food-induced, allergic reactions are mainly reported in patients with food220 dependent, exercise-induced anaphylaxis (FDEIA) (46) or in Lipid Transfer Protein (LTP)221 sensitized individuals from Mediterranean countries. A number of case reports or series have 222 been published $(9,47)$. In a French case-control study, the odds ratios for severe food-induced 223 anaphylaxis associated with aspirin and other NSAIDs were 10.8 and 8.2 respectively (48). A 224 third (11/34) of food-induced anaphylaxis in LTP syndrome patients were cofactor-dependent 225 (mainly NSAID) by history in one recent study (aspirin, ibuprofen, diclofenac, metamizol) (49). In 226 another retrospective study, 58\% (43/74) of patients with co-factor-induced mainly LTP-mediated 227 food allergy, NSAID was identified as a major co-factor (50). 
229 In just a few cases, the effect of NSAIDs on the manifestation of food allergy has been assessed 230 in vivo. Matsukura (46) observed an anaphylactic reaction in two patients under combined aspirin 231 and wheat challenge and Matsuo (51) observed allergic reactions in three other patients in a 232 similar setting. Brockow et al. has investigated aspirin as a cofactor for WDEIA, performing gluten 233 challenges under exercise with aspirin intake but unfortunately aspirin was combined with alcohol 234 as a second and therefore confounding cofactor (52). One hypothesis for the NSAID-related 235 enhancement of food allergy is the induction of increased gastrointestinal barrier permeability by 236 affecting the function of gastric epithelial tight junctions, which may increase the absorption of 237 allergens (53). Elevated gliadin concentration in serum has been observed with NSAID intake in a 238 dose-dependent manner, even in low-dose-aspirin treatment $(46,51,52,55)$. Another hypothesis 239 postulated is a direct NSAID effect on mast cell function $(9,56)$ and basophils $(57)$.

241 Angiotensin-converting enzyme (ACE) inhibitors and beta-blocking agents

242 Both drugs have been reported to aggravate allergic reactions (refs) although other studies would 243 disagree (58-62). In a French case-control study, the odds ratios for severe anaphylaxis with co244 existing beta-blocker and ACE inhibitors treatment were 6.8 and 13.0 respectively (48). Risk 245 factor analysis in 4783 patients from the anaphylaxis registry of the German-speaking countries 246 calculated a modest but significant increase of odds ratio (OR increase) for the combined use of 247 these drugs $(63,64)$. Comparing patients (adjusted for age and sex) with severity grade $1 / I I$ versus 248 grade III/IV, there was no significant effect for isolated ACE inhibitor or beta-blocker intake. There 249 was only a significant effect observed for the isolated beta-blocker intake if grades I to III versus 250 grade IV were analysed (64). These data were supported by a mouse model (63). Nevertheless, 251 more studies are needed to assess the impact of ACE inhibitors and beta-blockers on the severity 252 of allergic reactions.

\section{The impact of exercise and physiological stress on severity of allergic reactions}

255 Other potential co-factors are exercise and physiological stress (eg sleep deprivation). They may 256 also be responsible for some of the large variation in severity of allergic reactions in individual 257 patients. One approach to look at this is to focus on threshold doses, the smallest amount of 258 allergen required to induce an allergic reaction in individuals. Population dose-distribution curves 259 describe the proportion of a population with a specific food allergy who will react to increasing 260 doses of the allergen (Figure 1). Co-factors may be able to shift population dose-distribution 261 curves to the left, resulting in a higher proportion of reactions at a lower dose and potentially 
262 increasing the severity of the reaction. Conversely, as described previously, other co-factors may 263 have the opposite effect (e.g. remind readers of one) and shift the dose-distribution curves 264 towards a less sensitive population (Figure 1). Understanding these population-based dose265 distribution curves, the factors which might impact upon them, and the magnitude of this effect is 266 crucial to guide the advice about when precautionary allergen labelling (PAL) should be applied to 267 food products. With better informed models, higher reference doses for governmental and 268 industry-based food allergen management programs may be acceptably safe (65).

270 These questions have led to the development of the Threshold Reactivity Clinical Evaluation 271 (TRACE) Study, associated with the iFAAM consortium and funded by the United Kingdom Food 272 Standards Agency. One hundred peanut-allergic adults are being challenged with peanut: an 273 initial baseline peanut challenge to establish their threshold, and then three further challenges in 274 a random order, including one after sleep deprivation, another with concurrent exercise and a 275 repeat baseline challenge. A comparison of challenges with and without sleep deprivation and 276 exercise will allow within-patient variability on threshold to be determined, as well as any 277 additional impact of sleep deprivation and exercise on the threshold for reactivity. Additionally, the 278 study offers the opportunity to also look at the impact of these co-factors on reaction severity and 279 will provide dose-distribution modelling for a UK adult population.

281 These data will be important in informing better allergen management in the food industry as they 282 should provide a more robust evidence base for harmonised reference doses and therefore 283 action levels (65). TRACE will report in 2019.

\section{4}

285

286 


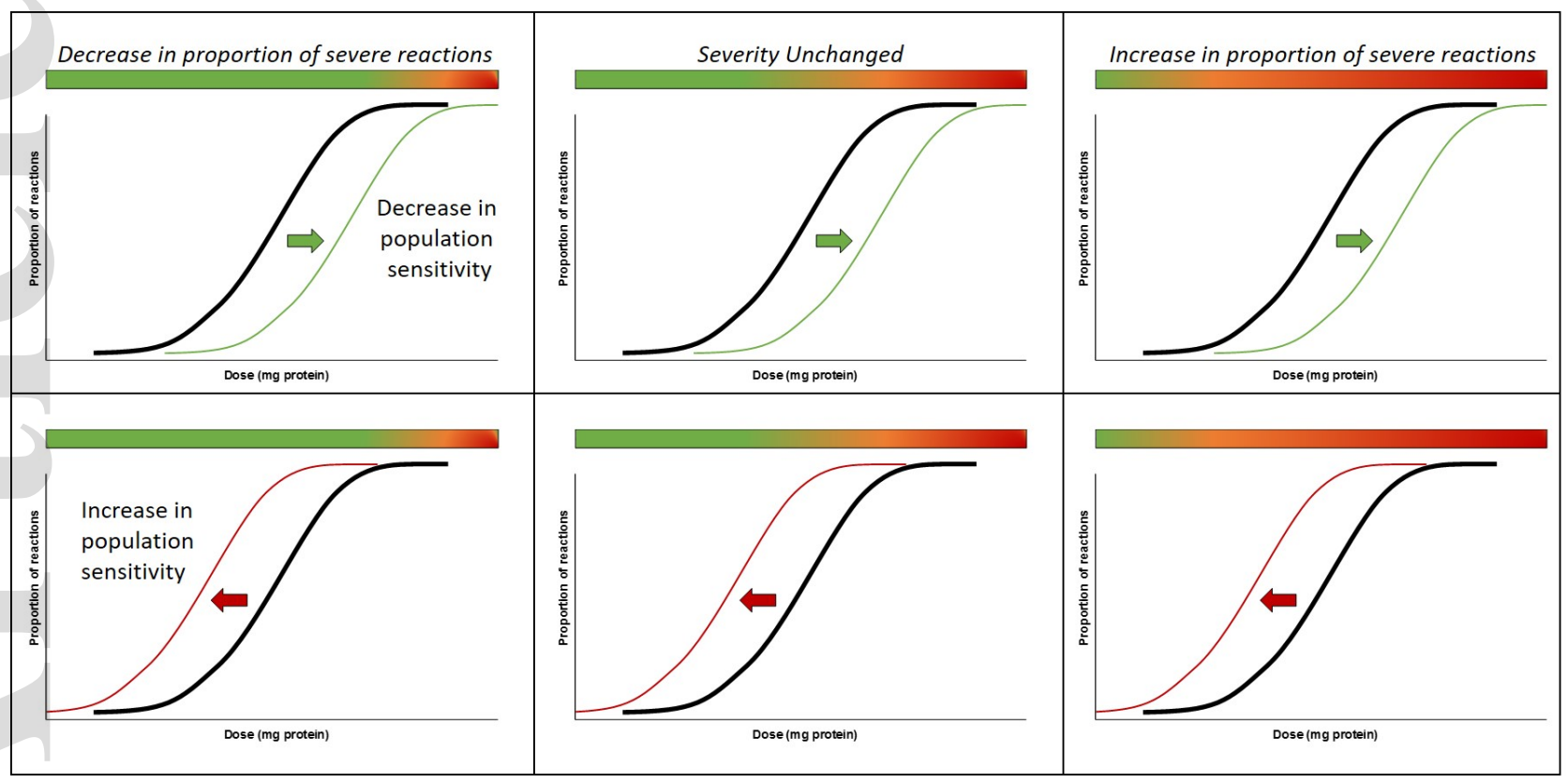

291 Extrinsic factors may influence both the threshold and severity of allergic reactions. They may 292 reduce the threshold dose that induces an allergic reaction in a percentage of the allergic 293 population (bottom line) while reducing (left) or increasing (right) the severity of reactions. Other 294 extrinsic factors may have the opposite effect increasing the threshold dose that induces an 295 allergic reaction in a percentage of the allergic population (top line) and either reducing (left) or 296 increasing (right) the severity of reactions. See also Hourihane and Knulst (66).

\section{What can we learn from single dose challenges?}

300 Population dose-distribution modelling of individual threshold doses can be used to establish 301 public health measures such as the control of PAL. These dose-distribution curves can be used 302 to define reference doses. For example, the dose eliciting a reaction in $1 \%$ of individuals with 303 peanut allergy (eliciting dose, $\mathrm{ED}_{01}$ ) has been estimated to be $0.2 \mathrm{mg}$ peanut protein, using log304 normal and log-logistic models $(67,68)$. The $\mathrm{ED}_{01}$ was selected by the VITAL Scientific Expert 305 Panel (VSEP) because it is predicted to protect $99 \%$ of the peanut-allergic population against any 306 reaction. This dose can be used to inform allergen action levels as decision points to apply PAL. 307 Alternatively a different protection goal could be chosen by using the $E D_{05}$, the dose at which $95 \%$ 308 of the population are protected (69); this has the advantage of giving higher action levels 309 involving potentially fewer products bearing PAL, albeit with more individuals remaining at risk of 
310 allergic reactions to unintentionally present allergen(s). Whatever the reference dose used, it is 311 clearly critical to confirm the benign nature of reactions at that dose, and particularly to ensure 312 that their nature and frequency remain tolerable in public health terms.

\section{3}

314 It is important that eliciting doses derived from dose-distribution models are validated. The 315 recently completed Peanut Allergen Threshold Study (PATS) has focused on the $E D_{05}$ for peanut 316 in a single dose $(66,69)$. Only $8 / 375(2.1 \%)$ subjects had convincing objective reactions according 317 to pre-defined criteria, all mild. In iFAAM, the same protocol has been applied to milk, egg and 318 hazelnut to validate the $\mathrm{ED}_{05}$ for each of these important allergens, albeit across much wider 319 confidence intervals, owing to smaller numbers of participants.

321 The single dose challenge protocol has important potential clinical application. It is very easy to 322 use and has been positively received by families, as it is much less time consuming than existing 323 cumulative dose food challenge protocols. Food allergy-related quality of life improved in both 324 non-reactors and reactors (66). $E D_{05}$ reactors could potentially be followed up by another single 325 dose protocol using the $\mathrm{ED}_{01}$ to better delineate their personal thresholds. Clinical services 326 without the resources for full cumulative dosing food challenges could use this single dose 327 approach safely, to identify the most dose-sensitive subjects. This could allow advice with regards 328 to PAL to be personalised.

330 Validation of the log-normal $\mathrm{ED}_{05}$ by these single dose studies, will hopefully motivate the 331 scientific, food industry and public health communities to adopt this quantitative approach to 332 decisions to use PAL, starting with the establishment of a defined and widely-accepted reference 333 dose for peanut in quantitative risk assessment. This would underpin a more evidence-based use 334 of PAL, by providing sound scientific evidence to protect the vast majority of the peanut allergic 335 community.

\section{How can community reactions help us to understand severity of allergic reactions?}

338 Clinical reactions to food mostly occur outside the hospital or clinic setting. It is therefore 339 important to explore severity in the community to ensure that similar patterns are seen to those 340 observed in hospital-based studies. Such community studies are challenging, as they are 341 inevitably observational and often retrospective, and reported severity may be prone to bias by 
342 patients' personal perception and experience. The "Allergic Reactions in the Community" 343 (AllerRIC/AlleRiSC: UK, Ireland) and "Allergic Reactions" (AlleREACT: UK, Ireland, Spain, 344 Germany, Poland) studies have attempted to address some of these problems by developing and 345 validating two online reporting tools for food allergic reactions in the community, allowing for 346 reporting of incidents in near real-time $(70,71)$. The AllerRIC/AlleRiSC study uses a multi-method, 347 longitudinal design which allows tracking of the same cohort of adult patients over a two-year 348 period (2014-2016). Adult patients with confirmed food allergies were asked to report their 349 reactions to food regardless of perceived severity, from mild incidents to anaphylaxis. Participants' 350 previous reactions and medical history were recorded in Clinical Record Forms in order to 351 compare the prospective incidence with the retrospective records. Additionally, a measure of 352 perceived severity was included in the reporting tool to explore relationships between perception 353 of severity (from 0 "extremely mild" to 9 "extremely severe) and reported symptoms $(70,71)$. Forty 354 food-allergic incidents were reported in Ireland and the UK between October 2014 and December 355 2016. Analyses showed a significant relationship between perceived severity, reported symptoms, 356 risk perception, and psychological impact (as measured on 5-item scale adapted from Positive 357 and Negative Affect Scale, PANAS). The related AlleREACT study has gathered real time data 358 via the internet on reactions in adults with food allergy and parents of affected children from the 359 UK, Ireland, Spain, Germany, France, and Poland. To date, over 400 reactions have been 360 reported with a wide variety of severities. Results from these studies will be available in 2019.

\section{Summary and conclusions}

364 Individuals experiencing severe allergic reactions to food make up an important subgroup, they 365 experience considerable morbidity, and while fatal reactions are rare, they are also unpredictable 366 (72,73). Within the iFAAM project, a Food Allergy Severity Score (FASS) has been developed 367 and validated. This has the potential to accurately describe previous allergic reactions at both a 368 simple and more complex level. Several iFAAM studies are examining the impact of the food 369 matrix on reaction severity; this would allow us to highlight which foods are particularly high risk 370 for affected individuals. The presence of co-factors may also impact reaction severity. iFAAM has 371 investigated the effect of proton-pump inhibitors, which are commonly prescribed, on DBPCFC to 372 walnut in a two centre study. The potential impact of exercise and sleep deprivation as co-factors

373 is also being examined in the associated TRACE study. Understanding the magnitude of the 374 impact of these potential co-factors on thresholds and severity will allow us to better advise 375 patients of scenarios which might place them more at risk, and provide guidance to public health 
376 authorities and the food industry on the level of unintended allergen presence in foods that are

377 likely to be safe for most individuals with food allergy. These decisions are being driven by 378 population dose-distribution curves, describing the relationship between dose of allergen and 379 likelihood of reaction; these are being validated by iFAAM using single dose challenges. This 380 approach also has the potential to improve patient experience as it is a relatively simple way of 381 identifying individuals who are likely to react to very small quantities of allergen. Finally iFAAM is 382 also attempting to understand the experience of individuals who have reactions in the community; 383 this will allow us to set the experimental studies in the context of real life and to integrate the 384 impact of biopsychosocial factors, such as physiological and psychological stress, into 385 subsequent multi-system models.

\section{Acknowledgements}

388 We would like to acknowledge the input of many of our iFAAM and other colleagues. For the 389 matrix work: Kirsten Beyer - Berlin; Joan Bartra - Barcelona; Karine Adel-Patient, Herve Bernard 390 - Paris; Harry Wichers - Wageningen; IFR Team: Marianne Defernez, Jack Dainty, Adam 391 Macierzanka, Ana Sancho, Neil Rigby, Alan Mackie; University of Manchester: Ivona Baricevic392 Jones, Phil Johnson, Justin Marsh, Rebekah Sayers, Anuradha Balasundaram, Bushra Javed, 393 Charlotte Hands, Carol Ann Costello, Huan Rao, Frances Smith, Phil Padfield; UHSM: Adnan 394 Custovic, Angela Simpson, Aida Semic-Jusufagic, Marina Themis; Allerg-e-lab: lain Buchan, Phil 395 Couch, Chris Munro, Matt Sperrin. For the severity score: Madrid: Ismael Gómez García, Cristina 396 Fernández Pérez. For the single-dose-challenges: Cork: Yvonne d’Art, June Considine, Gillian 397 Dunngalvin; FARRP: Steve Taylor, Joe Baumert, Julie Nordlee; Madrid: Guadalupe Marco Martín, 398 Ismael Gómez García; Valerie Trendelenburg - Berlin. PATS: Wayne Shreffler. For community 399 studies: Aida Semic-Jusufagic, Christopher Munro, Philip Couch, Marina Themis, Angela 400 Simpson; DAAB, Anaphylaxis Campaign (Moira Austin), AEPNAA (Pilar Hernandez), Yanne 401 Boloh, Anaphylaxis Ireland (Fiona Kenna, Deirdre Galloway). AMC: Mareen Datema, Koos 402 Zwinderman, serge Versteeg, Laurian Jongejan. For the proton pump inhibitor effect: Madrid: 403 Guadalupe Marco Martín, Ismael Gómez García, Isadora Suarez Lorenzo. We would also like to 404 acknowledge the support of ILSI in arranging the second workshop. 
410 1. Nwaru BI, Hickstein L, Panesar SS, Roberts G, Muraro A, Sheikh A on behalf of The EAACI 411 Food Allergy \& Anaphylaxis Guidelines Group. Prevalence of common food allergies in Europe: a 412 systematic review and meta-analysis. Allergy 2014; 69: 992-1007.

413 2. Venter, C., Arshad, SH., Grundy, J., Pereira, B., Clayton, BC., et al. (2010), Time trends in the 414 prevalence of peanut allergy: three cohorts of children from the same geographical location in the 415 UK. Allergy 2010; 65: 103-108.

416 3. Turner PJ, Gowland MH, Sharma V, lerodiakonou D, Harper N, Garcez T et al. Increase in 417 hospital admissions due to anaphylaxis but no increase in fatalities: an analysis of UK national 418 anaphylaxis data, 1992-2012. J Allergy Clin Immunol 2015;135:434-442

419 4. Panesar SS, Javad S, de Silva D, Nwaru BI, Hickstein L, Muraro A, et al. The epidemiology of 420 anaphylaxis in Europe: a systematic review. Allergy 2013;68: 1353-1361.

421 5. Muraro A, Werfel T, Hoffmann-Sommergruber K, Roberts G, Beyer K, Bindslev-Jensen C, et al. 422 EAACl food allergy and anaphylaxis guidelines: diagnosis and management of food allergy.

423 Allergy. 2014;69(8):1008-25

424 6. Salvilla SA, Dubois AEJ, Flokstra-de Blok BMJ, Panesar SS, Worth A, Patel S, et al. Disease425 specific health-related quality of life (HRQL) instruments for IgE-mediated food allergy. Allergy 426 2014; 69: 834-844.

427 7. Pumphrey RS, Gowland MH. Further fatal allergic reactions to food in the United Kingdom, 428 1999-2006. J Allergy Clin Immunol 2007;119:1018-1019.

429 8. Pettersson ME, Koppelman GH, Flokstra-de Blok BMJ, Kollen BJ, Dubois AEJ. Prediction of 430 the severity of allergic reactions to foods. Allergy 2018; 73; 1532-1540.

431 9. Wölbing F, Fischer J, Köberle M, Kaesler S, Biedermann T. About the role und underlying 432 mechanisms of cofactors in anaphylaxis. Allergy 2013; 68: 1085-92.

433 10. Mueller HL. Further experiences with severe allergic reactions to insect stings. N Engl J Med. $434 \quad 1959 ; 261: 374-7$.

435 11. Reisman RE. Natural history of insect sting allergy: relationship of severity of symptoms of 436 initial sting anaphylaxis to re-sting reactions. J Allergy Clin Immunol. 1992;90(3 Pt 1):335-9.

437 12. Hourihane JO, Kilburn SA, Dean P, Warner JO. Clinical characteristics of peanut allergy. Clin 438 Exp Allergy. 1997;27(6):634-9. 
439 13. Ewan PW, Clark AT. Long-term prospective observational study of patients with peanut and 440 nut allergy after participation in a management plan. Lancet. 2001;357(9250):111-5.

441 14. Brown SG. Clinical features and severity grading of anaphylaxis. J Allergy Clin Immunol. $442 \quad 2004 ; 114(2): 371-6$.

443 15. Cianferoni A, Garrett JP, Naimi DR, Khullar K, Spergel JM. Predictive values for food 444 challenge-induced severe reactions: development of a simple food challenge score. Isr Med 445 Assoc J. 2012;14(1):24-8.

446 16. Sampson HA. Anaphylaxis and emergency treatment. Pediatrics. 2003;111(6 Pt 3):1601-8.

447 17. Hourihane JO'B, Grimshaw KE, Lewis SA, Briggs RA, Trewin JB, King RM, et al. Does 448 severity of low-dose, double-blind, placebo-controlled food challenges reflect severity of allergic 449 reactions to peanut in the community? Clin Exp Allergy. 2005;35(9):1227-33.

450 18. Astier C, Morisset M, Roitel O, Codreanu F, Jacquenet S, Franck $P$, et al. Predictive value of 451 skin prick tests using recombinant allergens for diagnosis of peanut allergy. J Allergy Clin 452 Immunol. 2006;118(1):250-6.

453 19. Ring J, Messmer K. Incidence and severity of anaphylactoid reactions to colloid volume 454 substitutes. Lancet. 1977;1(8009):466-9.

455 20. Ring J. Anaphylactoid reactions to intravenous solutions used for volume substitution. Clin 456 Rev Allergy. 1991;9(3-4):397-414.

457 21. Lockey RF, Turkeltaub PC, Olive ES, Hubbard JM, Baird-Warren IA, Bukantz SC. The 458 Hymenoptera venom study. III: Safety of venom immunotherapy. J Allergy Clin Immunol. $459 \quad 1990 ; 86(5): 775-80$.

460 22. Golden DB, Kwiterovich KA, Kagey-Sobotka A, Lichtenstein LM. Discontinuing venom 461 immunotherapy: extended observations. J Allergy Clin Immunol. 1998 Mar;101(3):298-305.

462 23. Muraro A, Fernandez-Rivas M, Beyer K, Cardona V, Clark A, Eller E, et al. The urgent need 463 for a harmonized severity scoring system for acute allergic reactions. Allergy, in press.

464 24. Fernández-Rivas $M$, Barreales L, Mackie AR, Fritsche $P$, Vázquez-Cortés S, Jedrzejczak465 Czechowicz $M$, et al. The EuroPrevall outpatient clinic study on food allergy: background and 466 methodology. Allergy. 2015;70(5):576-84.

467 25. Sensoy I. A review on the relationship between food structure, processing, and bioavailability. 468 Crit Rev Food Sci Nutr 2014;54(7):902-909. 
469 26. Fernández-García E, Carvajal-Lérida I, Pérez-Gálvez A. In vitro bioaccessibility assessment 470 as a prediction tool of nutritional efficiency. Nutrition Research 2009;29(11):751-760.

471 27. Grimshaw KE, King RM, Nordlee JA, Hefle SL, Warner JO, Hourihane JO'B. Presentation of 472 allergen in different food preparations affects the nature of the allergic reaction--a case series. 473 Clin Exp Allergy 2003;33(11):1581-1585.

474 28. Mackie A, Knulst A, Le TM, Bures $P$, Salt L, Mills EN, et al. High fat food increases gastric 475 residence and thus thresholds for objective symptoms in allergic patients. Mol Nutr Food Res $476 \quad 2012 ; 56(11): 1708-1714$.

477 29. Goldberg MR, Nachshon L, Appel MY, Elizur A, Levy MB, Eisenberg E, et al. Efficacy of 478 baked milk oral immunotherapy in baked milk-reactive allergic patients. J Allergy Clin Immunol $479 \quad 2015 ; 136(6): 1601-1606$.

48030 Libbers L, Flokstra-de Blok BMJ, Vlieg-Boerstra BJ, van der Heide S, van der Meulen GN, 481 Kukler J, et al. No matrix effect in double-blind, placebo-controlled egg challenges in egg allergic 482 children Clinical \& Experimental Allergy,2013; (43) 1067-1070.

483 31. Remington BC, Westerhout J, Campbell DE, Turner PJ. Minimal impact of extensive heating 484 of hen's egg and cow's milk in a food matrix on threshold dose-distribution curves. Allergy $485 \quad 2017 ; 72: 1816-9$.

486 32. Worm M, Hompes S, Fiedler EM, IIIner AK, Zuberbier T, Vieths S. Impact of native, heat487 processed and encapsulated hazelnuts on the allergic response in hazelnut-allergic patients. 488 Clinical and Experimental Allergy 2009;39(1):159-166.

489 33. Asarnoj A, Nilsson C, Lidholm J, Glaumann S, Östblom E, Hedlin G, van Hage M, Lilja G, 490 Wickman M. Peanut component Ara h 8 sensitization and tolerance to peanut. J Allergy Clin 491 Immunol. 2012;130(2):468-72.

492 34. F. Husslik, J. Nürnberg, C. Seutter von Loetzen, T. Mews, B. K. Ballmer - Weber, J. Kleine 493 - Tebbe, et al. The conformational IgE epitope profile of soya bean allergen Gly $m$ 4. Clin Exp 494 Allergy 2016; 46: 1484-1497.

495 35. Sampson HA, Aceves S, Bock SA, James J, Jones S, Lang D, et al. Food allergy: a practice 496 parameter update-2014. J Allergy Clin Immunol. 2014;134(5):1016-25.

497 36. Santos AF, James LK, Bahnson HT, Shamji MH, Couto-Francisco NC, Islam S, Houghton S, 498 Clark AT, Stephens A, Turcanu V, Durham SR, Gould HJ, Lack G. IgG4 inhibits peanut-induced 
499 basophil and mast cell activation in peanut-tolerant children sensitized to peanut major allergens.

$500 \quad J$ Allergy Clin Immunol. 2015;135(5):1249-56.

501 37. M.R. Datema, E. Eller, A.H. Zwinderman, L.K. Poulsen, S.A.Versteeg, R. van Ree, Carsten 502 Bindslev-Jensen. Ratios of specific IgG4 over IgE antibodies do not improve prediction of peanut 503 allergy nor of its severity compared to specific IgE alone. Clin Exp Allergy 2018 in press.

504 38. Korosec P, Turner PJ, Silar M, Kopac P, Kosnik M, Gibbs MF, et al. Basophils, high-affinity 505 IgE receptors, and CCL2 in human anaphylaxis. J Allergy Clin Immunol 2017; 140: 750-758.

506 39. Dirks CG, Pedersen MH, Platzer MH, Bindslev-Jensen C, Skov PS, Poulsen LK. Does 507 absorption across the buccal mucosa explain early onset of food-induced allergic systemic 508 reactions? J Allergy Clin Immunol. 2005;115(6):1321-3.

509 40. Krohn,I.K. et al. Cultured mast cells from asthmatic patients and controls respond with similar 510 sensitivity to recombinant Der P2 induced, IgE-mediated activation. Scand. J. Immunol.(2013).

511 41. Kuehn,H.S., Jung,M.Y., Beaven,M.A., Metcalfe,D.D., \& Gilfillan,A.M. Distinct PGE2-responder 512 and non-responder phenotypes in human mast cell populations: "all or nothing" enhancement of 513 antigen-dependent mediator release. Immunol. Lett.2011; 141: 45-54.

514 42. Miner PB. Physiologic and clinical effects of proton pump inhibitors on non-acidic and acidic 515 gastro-oesophageal reflux. Alimentary Pharmacology \& Therapeutics 2006; 23: 25-32.

516 43. Pali-Schöll I, Jensen-Jarolim E. Anti-acid medication as a risk factor for food allergy. Allergy. $517 \quad 2011 ; 66(4): 469-77$.

518 44. Schöll I, Untersmayr E, Bakos N, Roth-Walter F, Gleiss A, Boltz-Nitulescu G, et al. Antiulcer 519 drugs promote oral sensitization and hypersensitivity to hazelnut allergens in BALB/c mice and 520 humans. Am J Clin Nutr. 2005; 81(1):154-60.

521 45. Untersmayr E, Vestergaard H, Malling HJ, Jensen LB, Platzer MH, Boltz-Nitulescu G, et al. 522 Incomplete digestion of codfish represents a risk factor for anaphylaxis in patients with allergy. $J$ 523 Allergy Clin Immunol. 2007;119(3):711-7.

524 46. Matsukura S, Aihara M, Sugawara M, Kunimi Y, Matsuki M, Inoue Y, Kambara T, Ikezawa Z. 525 Two cases of wheat-dependent anaphylaxis induced by aspirin administration but not by exercise.

526 Clin Exp Dermatol. 2010; 35(3):233-7.

527 47. Cant AJ, Gibson P, Dancy M. food hypersensitivity made life threatening by ingestion of 528 aspirin. Br Med J 1984; 288: 755-756.

This article is protected by copyright. All rights reserved 
529 48. Moneret-Vautrin DA, Latarche C. Drugs as risk factors of food anaphylaxis in adults: a case530 control-study. Bull Acad Natl Med. 2009;193:351-62

531 49. Pascal M, Muñoz-Cano R, Reina Z, Palacín A, Vilella R, Picado C, et al. Lipid transfer protein 532 syndrome: clinical pattern, cofactor effect and profile of molecular sensitization to plant-foods and 533 pollens. Clin Exp Allergy. 2012;42(10):1529- 39.

534 50. Cardona V, Luengo O, Garriga T, Labrador-Horrillo M, Sala-Cunill A, Izquierdo A, Soto L, 535 Guilarte M. Cofactor- enhanced food allergy. Allergy. 2012;67(10):1316-8.

536 51. Matsuo H, Morimoto K, Akaki T, Kaneko S, Kusatake K, Kuroda T, et al. Exercise and aspirin 537 increase levels of circulating gliadin peptides in patients with wheat-dependent exercise induced 538 anaphylaxis. Clin Exp Allergy. 2005;35(4):461-6.

539 52. Brockow K, Kneissl D, Valentini L, Zelger O, Grosber M, Kugler C, et al. Using a gluten oral 540 food challenge protocol to improve diagnosis of wheat-dependent exercise induced anaphylaxis. 541 J Allergy Clin Immunol. 2015;135(4):977-84.

542 53. Oshima T, Miwa H, Joh T. Aspirin induces gastric epithelial barrier dysfunction by activating 543 p38 MAPK via claudin-7. Am J Physiol Cell Physiol. 2008;295(3):C800-6

544 54. Matsuo H, Kaneko S, Tsujino Y, Honda S, Kohno K, Takahashi H, et al. Effects of non545 steroidal anti-inflammatory drugs (NSAIDs) on serum allergen levels after wheat ingestion. 546 Dermatol Sci. 2009;53(3):241-3.

547 55. Fujii H, Kambe N, Fujisawa A, Kohno K, Morita E, Miyachi Y. Food-dependent exercise548 induced anaphylaxis induced by low dose aspirin therapy. Allergol Int. 2008;57(1):97-8.

549 56. Mortaz E, Redegeld FA, Nijkamp FP, Engels F. Dual effects of acetylsalicylic acid on mast 550 cell degranulation, expression of cyclooxygenase-2 and release of pro-inflammatory cytokines. 551 Biochem Pharmacol. 2005;69(7):1049-57.

552 57. Pascal M, Muñoz-Cano R, Milà J, Sanz ML, Diaz-Perales A, Sánchez-López J, et al. 553 Nonsteroidal anti-inflammatory drugs enhance lgE-mediated activation of human basophils in 554 patients with food anaphylaxis dependent on and independent of nonsteroidal anti-inflammatory 555 drugs. Clin Exp Allergy. 2016;46(8):1111-9.

556 58. Ruëff F, Przybilla B, Biló MB, Müller U, Scheipl F, Aberer W, et al. Predictors of side effects 557 during the build up phase of venom immunotherapy for Hymenoptera venom allergy: the 558 importance of baseline serum tryptase. J Allergy Clin Immunol. 2010;126(1):105-11 
559 59. Ruëff F, Przybilla B, Biló MB, Müller U, Scheipl F, Aberer W, et al. Predictors of severe 560 systemic anaphylactic reactions in patients with Hymenoptera venom allergy: importance of 561 baseline serum tryptase-a study of the European Academy of Allergology and Clinical

562 Immunology Interest Group on Insect Venom Hypersensitivity. J Allergy Clin Immunol. 563 2009;124(5):1047-54.

564 60. Stoevesandt J, Hain J, Kerstan A, Trautmann A. Over- and underestimated parameters in 565 severe Hymenoptera venom-induced anaphylaxis: cardiovascular medication and absence of 566 urticaria/angioedema. J Allergy Clin Immunol. 2012;130(3):698-704

567 61. Stoevesandt J, Hosp C, Kerstan A, Trautmann A. Hymenoptera venom immunotherapy while 568 maintaining cardiovascular medication: safe and effective. Ann Allergy Asthma Immunol. $5692015 ; 114(5): 411-6$.

570 62. Summers CW, Pumphrey RS, Woods CN, McDowell G, Pemberton PW, Arkwright PD.

571 Factors predicting anaphylaxis to peanuts and tree nuts in patients referred to a specialist center. 572 Journal of Allergy and Clinical Immunology. 2008; 121(3):632-e2.

573 63. Nassiri M, Babina M, Dölle S, Edenharter G, Ruëff F, Worm M. Ramipril and metoprolol intake 574 aggravate human and murine anaphylaxis: Evidence for direct mast cell priming. J Allergy Clinical 575 Immunol 2015; 135: 491-499.

576 64. Worm M, Francuzik W, Renaudin JM, Bilo MB, Cardona V, Scherer Hofmeier K, Köhli A, 577 Bauer A, Christoff G, Cichocka - Jarosz E, Hawranek T. Factors increasing the risk for a severe 578 reaction in anaphylaxis: An analysis of data from The European Anaphylaxis Registry. Allergy. 579 2018; 73: 1322-1330.

580 65. DunnGalvin A, Chan C-H, Crevel R, Grimshaw K, Poms R, Schnadt S, et al. Precautionary 581 allergen labelling: perspectives from key stakeholder groups. Allergy 2015; 70: 1039-51.

582 66. JO'B Hourihane, AC Knulst. Thresholds of allergenic proteins in foods. Toxicology Applied 583 Pharmacology. 2005;207(2 Suppl):152-6.

584 67. Taylor, S.L., Baumert, J.L., Kruizinga, A.G., Remington, B.C., Crevel, R.W.R., \& Brooke585 Taylor, S. (2014) Food Chem.Toxicol. 63, 9-17. doi:10.1016/j.fct.2013.10.032

586 68. Allen KJ, Remington BC, Baumert JL, Crevel RWR, Houben GF, Brooke-Tayler S, Kruizinga 587 AG, Taylor SL (2014) Allergen reference doses for precautionary labeling (VITAL 2.0): clinical 588 implications. Journal of Allergy and Clinical Immunology 133:156-64 
589 69. Hourihane JO'B, Allen KJ, Shreffler WG, Dunngalvin G, Nordlee JA, Dunngalvin A, et al.

590 Peanut Allergen Threshold Study (PATS): Novel single-dose oral food challenge study to validate 591 eliciting doses in peanut allergic children. J Allergy Clin Immunol, 2017; 139: 1583-1590.

592 70. Munro C, Semic-Jusufagic A, Pyrz K, Couch P, Dunn-Galvin A, Peek N, et al. An eHealth 593 Approach to Reporting Allergic Reactions to Food and Closing the Knowledge Gap. Studies in 594 health technology and informatics. 2015;216:320-4.

595 71. Pyrz KS-J, A.; Munro, Ch.; Couch, P.; Mills, C.; Hourihane, J.; Dunn Galvin, A. Developing 596 and validating a novel questionnaire to capture bio-psycho-social variables of allergic reactions in 597 the community: the AlleRiC study and the preliminary analyses. Clinical and Translational Allergy 598 2015; 5(Suppl 3):P1.

599 72. Turner PJ, Baumert JL, Beyer K, Boyle RJ, Chan CH, Clark AT, et al. Can we identify patients 600 at risk of life-threatening allergic reactions to food? Allergy. 2016 Sep;71(9):1241-55.

601 73. Hanna HJ, Emmanuel J, Naim S, Umasunthar T, Boyle RJ. Community healthcare 602 professionals overestimate the risk of fatal anaphylaxis for food allergic children. Clin Exp Allergy. 603 2016;46(12):1588-1595. 